\title{
Pediatric unmanipulated haploidentical hematopoietic stem cell transplantation with post-transplant cyclophosphamide and reduced intensity, TBI-free conditioning regimens in salvage transplantations
}

\author{
Elżbieta Wawrzyniak-Dzierżek ${ }^{A-F}$, Kornelia Gajek ${ }^{B, C, E, F}$, Aleksandra Ślęzak ${ }^{B, C, E, F}$, Blanka Rybka ${ }^{B, C, E, F}$, \\ Renata Ryczan-Krawczyk ${ }^{B, C, E, F}$, Ewa Gorczyńska ${ }^{\mathrm{E}, \mathrm{F}}$, Krzysztof Kałwak ${ }^{\mathrm{E}, \mathrm{F}}$, Marek Ussowicz ${ }^{\mathrm{A}-\mathrm{F}}$ \\ Department of Pediatric Bone Marrow Transplantation, Oncology and Hematology, Wroclaw Medical University, Poland \\ A - research concept and design; B - collection and/or assembly of data; C - data analysis and interpretation; \\ $D$ - writing the article; $E$ - critical revision of the article; $F$ - final approval of the article
}

Address for correspondence

Marek Ussowicz

E-mail: ussowicz@tlen.pl

Funding sources

Wroclaw Medical University statutory grant ST-781 (ST.C200.13.013)

Conflict of interest

None declared

Received on August 7, 2018

Reviewed on December 10, 2018

Accepted on February 25, 2019

Published online on August 19, 2019

Cite as

Wawrzyniak-Dzierżek E, Gajek K, Ślęzak A, et al. Pediatric unmanipulated haploidentical hematopoietic stem cell transplantation with post-transplant cyclophosphamide and reduced intensity, TBI-free conditioning regimens in salvage transplantations. Adv Clin Exp Med. 2019;28(9):1223-1228 doi:10.17219/acem/104688

DOI

10.17219/acem/104688

Copyright

Copyright by Author(s)

This is an article distributed under the terms of the

Creative Commons Attribution Non-Commercial License

(http://creativecommons.org/licenses/by-nc-nd/4.0/)

\begin{abstract}
Background. Unmanipulated haploidentical stem cell transplantation (haploSCT) with post-transplant cyclophosphamide is an option for patients with advanced hematologic malignancies. It offers a platform both for non-major histocompatibility complex-restricted alloimmunity due to killer-like immunoglobulin receptor (KIR)-mediated mechanisms of natural killer lymphocyte regulation and for classical T-cell mediated antileukemic effects.
\end{abstract}

Objectives. The devastating long-term sequelae after total body irradiation (TBI) in children are encouraging omission of irradiation techniques in pediatric stem cell transplantations (SCT).

Material and methods. Five children, 4 with acute leukemia and 1 with hemophagocytic lymphohistiocytosis, aged from 1 to 10 years, underwent haploSCT with post-transplantation cyclophosphamide. In all children, the conditioning regimen consisted of chemotherapy without TBI. The graft material was bone marrow (BM) in 4 cases and peripheral blood stem cells in 1 case. Three out of 5 leukemic patients showed better KIR haplotype associated with augmented alloreactivity.

Results. Engraftment with complete donor chimerism was achieved in 4 patients, and 1 recipient died before leukocyte recovery. Three patients developed skin acute graft-versus-host-disease (aGvHD), 1 gut aGvHD and 1 liver aGVHD. In 2 recipients, chronic graft-versus-host-disease (CGvHD) was observed $(1$ limited and 1 extensive). The 4 engrafted patients were alive and in complete remission 3, 9, 32, and 36 months after transplantation. A T-cell count of 200 cells/UL was reached 90 days after haploSCT in all patients.

Conclusions. HaploSCT with TBl-free protocols can be a viable option for heavily pretreated patients with advanced malignancies.

Key words: hematopoietic stem cell transplantation, pediatric, haploidentical, post-transplant cyclophosphamide, TBl-free 


\section{Introduction}

The limited availability of matched stem cell donors was, in the past, a vital problem for patients requiring allogeneic stem cell transplantation (SCT) because partially matched donors could not have been accepted due to the high risk of a fatal graft-versus-host-disease (GvHD) and high risk of rejection. The first successful attempt in SCT crossing the human leukocyte antigen barrier was achieved in 1983 with the development of T-lymphocyte depletion by differential agglutination with soybean agglutinin (SBA) and subsequent E-rosette depletion. ${ }^{1}$ Haploidentical stem cell transplantation (haploSCT) had become a part of transplant methods in children since the introduction of immunomagnetic selection in $1996 .{ }^{2}$ Techniques enabling physical removal of donor T-lymphocytes from the graft material were highly effective, but high cost and the requirements for an established graft processing lab were limiting interest in haploSCT despite further refinements. Another milestone in haploSCT was marked by successful application of post-transplantation GvHD prophylaxis with cyclophosphamide (PTCY), ${ }^{3}$ which in turn started an avalanche of clinical trials with unmanipulated (T-cell replete) haploSCT. Cyclophosphamide administered from $48 \mathrm{~h}$ to $72 \mathrm{~h}$ after haploSCT eliminates T lymphocytes that have been activated by recognition of host minor histocompatibility antigens and prevents GvHD. ${ }^{3}$ Still, despite successful engraftment after PTCY, the patients can develop acute GvHD (aGvHD) and chronic GvHD (cGvHD), although with incidence rates comparable with matched donor transplantations. The most popular conditioning regimen in PTCY is the total body irradiation (TBI)-containing Baltimore protocol. ${ }^{4}$ Administration of TBI in children is restricted below the age of 3 and older children can require a TBI procedure under sedation. Due to the many limitations and unacceptable TBI-related late effects, radiotherapy-free conditioning regimens are being investigated in children. 5,6

HaploSCT offers a platform both for non-major histocompatibility complex-restricted natural killer (NK)-lymphocyte alloimmunity and for classical T-cell mediated antileukemic effects. Killer-like immunoglobulin receptors (KIR) are involved in the activation or inhibition of NK-cells, and KIR genes constitute an inheritable haplotype on chromosome 19. Two basic KIR haplotypes can be found in humans: group A, containing predominantly inhibitory receptors (with the exception KIR2DS4), and group B haplotypes, with combinations of 1 or more B-specific genes: KIR2DS1, KIR2DS2, KIR2DS3, KIR2DS5, KIR2DL2, and KIR2DL5. ${ }^{7,8}$

\section{Material and methods}

In the years 2014-2018, in the local Department of Pediatric Hematology and Oncology at Wroclaw Medical University, Poland, 5 children underwent haploSCT with PTCY GvHD prophylaxis. The medical procedures and this retrospective study were conducted according to local
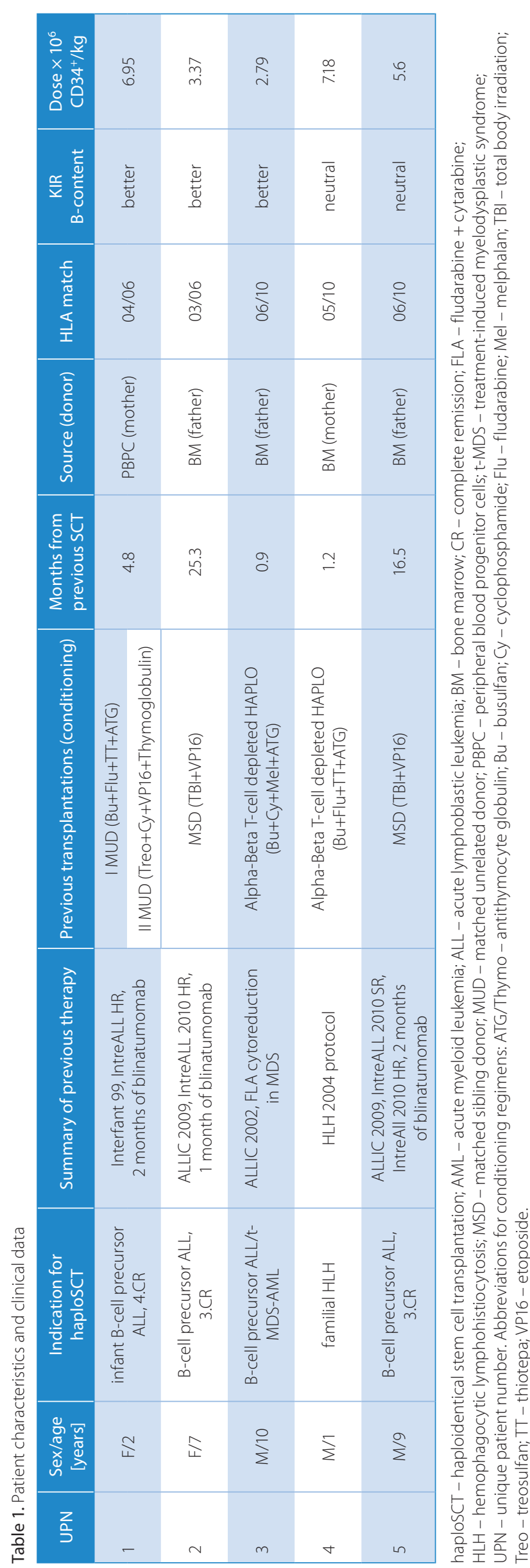
Table 2. Patient post-transplant data

\begin{tabular}{|c|c|c|c|c|c|c|c|}
\hline UPN & Engraftment & $\begin{array}{l}\text { Opportunistic } \\
\text { infections in post- } \\
\text { transplant period }\end{array}$ & $\begin{array}{l}\text { Non-hematologic } \\
\text { toxicities } \\
>\text { grade } 2\end{array}$ & $\begin{array}{l}\text { GvHD acute } \\
\text { or chronic }\end{array}$ & GvHD therapy & $\begin{array}{l}\text { GvHD } \\
\text { outcome }\end{array}$ & Follow-up \\
\hline 1 & donor $100 \%$ & neutropenic fever & mucositis & $\begin{array}{l}\text { aGvHD skin III, } \\
\text { gut III } \\
\text { Chronic GvHD } \\
\text { extensive. }\end{array}$ & $\begin{array}{l}\text { aGvHD: methylpredniosolone } \\
2 \mathrm{mg} / \mathrm{kg} \text {, tapered and } \\
\text { discontinued at }+3 \text { months, } \\
\text { etanercept discontinued } \\
\text { at }+2 \text { months. } \\
\text { cGvHD: treated with steroids } \\
\text { and mycophenolate mofetil }\end{array}$ & $C R$ & alive in $4^{\text {th }} C R$ \\
\hline 2 & donor $100 \%$ & neutropenic fever & mucositis & $\begin{array}{l}\text { aGvHD skin III/ } \\
\text { chronic limited }\end{array}$ & $\begin{array}{l}\text { methylpredniosolone } 1 \mathrm{mg} / \mathrm{kg} \text {, } \\
\text { tapered and discontinued at + } \\
2 \text { months }\end{array}$ & $C R$ & alive in $3^{\text {rd }} C R$ \\
\hline 3 & not achieved & $\begin{array}{l}\text { Achromobacter } \\
\text { xylosoxidans sepsis }\end{array}$ & mucositis & not applicable & - & not applicable & $\begin{array}{l}\text { died - non- } \\
\text { relapse } \\
\text { mortality }\end{array}$ \\
\hline 4 & donor $100 \%$ & $\begin{array}{l}\text { neutropenic fever, } \\
\text { CMV replication, } \\
\text { possible splenic } \\
\text { candidiasis }\end{array}$ & mucositis & $\begin{array}{l}\text { aGvHD skin II, } \\
\quad \text { liver II }\end{array}$ & $\begin{array}{l}\text { methylpredniosolone } 2 \text { mg/kg, } \\
\text { tapered }\end{array}$ & $\begin{array}{l}\text { partial } \\
\text { response, } \\
\text { on therapy }\end{array}$ & alive in $C R$ \\
\hline 5 & donor $100 \%$ & $\begin{array}{l}\text { neutropenic fever, } \\
\text { CMV replication }\end{array}$ & mucositis & no & - & not applicable & alive in $3^{\text {rd }} C R$ \\
\hline
\end{tabular}

UPN - unique patient number; CR - complete remission; GvHD - graft-versus-host-disease; aGvHD - acute graft-versus-host-disease; cGvHD - chronic graft-versus-host-disease; CMV - cytomegalovirus.

regulations. Demographic and clinical data is presented in Table 1. The choice of haploidentical donor was justified by the unavailability of a matched donor at the time of planned transplantation. All recipients had experienced failures of 1 or 2 allogeneic transplantations, with at least 1 based on full intensity, myeloablative conditioning, and the time from previous transplantation in the range of 0.9 25.3 months. Two out of 3 patients with acute lymphoblastic leukemia relapsing after SCT (UPN 1 and 2) were conditioned with a modified FCM (fludarabine, cyclophosphamide and melphalan) protocol, and 1 (UPN 5) with treosulfan, fludarabine and thiotepa. Finally, 2 patients (UPN 3 and 4) underwent transplant after rejection of alpha-beta T-cell depleted haploidentical grafts. Patient UPN 3, who was aplastic at the time of salvage transplantation, was treated with treosulfan and fludarabine. Patient UPN 4 showed previous graft rejection with autologous recovery and underwent a second transplantation with treosulfan, fludarabine and cyclophosphamide. Melphalan in patients 1 and 2 and treosulfan in patients $3-5$ were added due to contraindications for TBI therapy. The conditioning regimen details are shown in Table 2. The graft source was bone marrow (BM) in 4 cases and peripheral blood apheresis (PBPC) in 1 case. Post-transplant immunosuppression consisted of 2 cyclophosphamide doses on days +3 and +4 after transplantation. Cyclosporine and mycophenolate mofetil were used in all recipients from the $5^{\text {th }}$ day after haploSCT.

\section{Infection prophylaxis}

Herpes simplex virus and varicella-zoster virus prophylaxis included intravenous acyclovir $(5-10 \mathrm{mg} / \mathrm{kg}$ or
$250-500 \mathrm{mg} / \mathrm{m}^{2}$ every $\left.8 \mathrm{~h}\right)$ or, if tolerated, oral $(10 \mathrm{mg} / \mathrm{kg}$ every 6 h). Prophylaxis with trimethoprim-sulfamethoxazole against Pneumocystis jirovecii pneumonia was started after neutrophil engraftment and continued for as long as immunosuppressive therapy was given. Granulocytecolony stimulating factor at a dose of $5 \mu \mathrm{g} / \mathrm{kg}$ per day was started at day 5 after haploSCT until a neutrophil count of $500 / \mu \mathrm{L}$ was reached. The weekly monitoring of plasma for the Epstein-Barr virus, cytomegalovirus (CMV), adenovirus, BK virus, and urine for adenovirus and BK virus was performed.

\section{KIR B-content analysis}

The DNA isolated from donor blood samples was used for KIR genotype testing with a KIR-typing kit (Miltenyi, Bergisch Gladbach, Germany). The genotyping results were used for calculation of B-content score groups classified as neutral/better/best according to relapse protection in T-cell replete unrelated donor transplantations for acute myeloid leukemia according to Cooley. ${ }^{7}$

Statistical analysis and data presentation were performed with the computer software GraphPad Prism (GraphPad Software, La Jolla, USA).

\section{Results}

The neutrophil recovery was achieved between days 10 and 18 in 4 patients (Fig. 1A). One patient died before leukocyte recovery on day +10 due to gut associated Achromobacter xylosoxidans sepsis. Three engrafted patients 
A

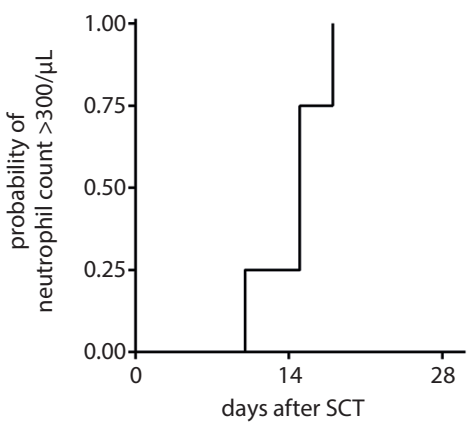

B

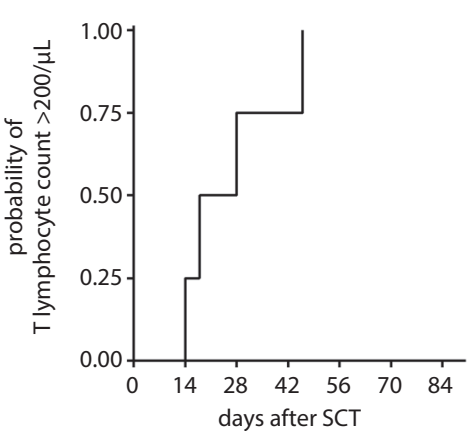

Fig. 1. Probability of absolute neutrophil recovery $>500 / \mu \mathrm{L}$ (A) and T-lymphocyte recovery $>200 / \mu \mathrm{L}$ (B) developed skin aGvHD (maximal stage III), 2 of them acute gut GvHD (both stage III) and 1 liver aGvHD (stage II). In 2 recipients, cGvHD was observed (1 limited, 1 extensive). All patients showed full donor chimerism from the time of engraftment. Immune recovery in all surviving patients occurred early, and in all patients, a complete T-lymphocyte count of 200 cells/ $\mu \mathrm{L}$ was reached before day +60 after transplantation (Fig. 1B). During the transplant period, CMV replication was diagnosed and treated in 1 patient, and asymptomatic BK virus viruria without signs of hemorrhagic cystitis was observed in 2 patients. None of the patients developed EBV- or adenovirus-related diseases. Immunosuppression was discontinued in UPN 2 6 months after haploSCT. At the time of this analysis, all 4 engrafted patients were alive, without significant comorbidities and in complete remission with normal blood results $3,9,32$, and 36 months after transplantation.

\section{Discussion}

Although at the moment of preparing this manuscript, the number of peer-reviewed papers on haploSCT with PTCY is over 400, the number of pediatric reports roughly constitutes $1 / 10$ of the whole number and a TBI-free strategy is published only in single papers. The advantage of haploSCT with PTCY lies in low cost, relatively low technical difficulty, easy access to haploidentical donors within the patient's family, and with transplant outcomes similar to matched unrelated donor transplantations., ${ }^{9,10}$ The next advance in haploSCT with PTCY is expected to be in the development of TBI-free conditioning, which can overcome the limited access to expensive and time-consuming techniques, especially in developing countries.

The strategy of PTCY GvHD prophylaxis can be combined with standard conditioning in different diseases, like in sickle cell disease, which was reported by Pawlowska. ${ }^{11}$ Llosa et al. included melphalan in the chemotherapy backbone, although without elimination of low-dose TBI. ${ }^{12}$ Similarly, Shima reported the combination of TBI with melphalan. ${ }^{13}$ The usage of TBI as a part of haploSCT with a PTCY regimen is continued even in patients with Fanconi anemia ${ }^{14,15}$ or in combination with busulfan. ${ }^{16}$ Some reports in adults have investigated the possibility of a TBI-free conditioning regimen by replacing it with thiotepa and melphalan, but the trial was complicated by limited access to thiotepa and the group reversed to TBI. ${ }^{17}$ The largest up-to-date pediatric study summarizing an Italian experience with 33 children transplanted with PTCY reported a subgroup of 10 patients treated with a myeloablative, busulfan-fludarabine-thiotepa regimen, and 2 with remote ischemic conditioning protocols, although the paper mentions some not-haploidentical transplantations, too. ${ }^{18}$ The TBI-free regimens can be based on busulfan containing regimens, although at risk of hepatic venoocclusive disease and might not be well-tolerated in heavily pretreated patients. A number of successful haploSCT

Table 3. Conditioning regimen details

\begin{tabular}{|c|c|c|c|c|c|c|c|c|c|c|}
\hline & Day before/after haploSCT & -6 & -5 & -4 & -3 & -2 & -1 & 0 & +3 & +4 \\
\hline UPN1, UPN2 & melphalan 4 mg/kg & & & & & & $\bullet$ & \multirow{8}{*}{ haplosCT } & & \\
\hline UPN3 & treosulfan $10 \mathrm{~g} / \mathrm{m}^{2}$ & & & $\bullet$ & $\bullet$ & $\bullet$ & & & & \\
\hline UPN4 & treosulfan $10 \mathrm{~g} / \mathrm{m}^{2}$ & $\bullet$ & $\bullet$ & & & & & & & \\
\hline \multirow{2}{*}{ UPN5 } & treosulfan $14 \mathrm{~g} / \mathrm{m}^{2}$ & - & - & - & & & & & & \\
\hline & thiotepa $2 \times 5 \mathrm{mg} / \mathrm{kg}$ & & & & & $\bullet$ & & & & \\
\hline \multirow{3}{*}{$\begin{array}{l}\text { Common } \\
\text { backbone }\end{array}$} & $\begin{array}{c}\text { cyclophosphamide } 14.5 \mathrm{mg} / \mathrm{kg} \\
\text { (except for UPN5) }\end{array}$ & - & - & & & & & & & \\
\hline & fludarabine 30 mg/m² & $\bullet$ & $\bullet$ & $\bullet$ & $\bullet$ & $\bullet$ & & & & \\
\hline & cyclophosphamide 50 mg/kg & & & & & & & & - & - \\
\hline
\end{tabular}

HaploSCT - haploidentical stem cell transplantation; UPN - unique patient number. 
procedures with busulfan-fludarabin regimen, PTCY and antithymocyte globulin (ATG) have been reported in upfront transplantations in primary immunodeficiencies, ${ }^{19,20}$ and by Bahr in malignant infantile osteopetrosis. ${ }^{21}$

Our paper shows experience with TBI-free preparative regimens in heavily pretreated patients, who were spared from toxic and myeloablative protocols, which can help in establishing new transplant standards. The conditioning regimens were given as a part of salvage therapies for highly resistant disease in heavily pretreated patients or after rejection of graft from the same donor. The FCM protocol presented in our series of patients was well-tolerated and proved its potential for full donor engraftment.

The choice of drugs in reduced intensity conditioning has not been established in the pediatric population. Previously-reported experiences with treosulfan-based transplantations in children were an encouraging alternative conditioning regimen in patients who rejected the first transplantation. ${ }^{6}$ The immunosuppressive properties of treosulfan against antigen-presenting cells and T-lymphocytes supported its administration in children that had recently experienced graft rejection from the same donor. ${ }^{22}$ Low-intensity conditioning with the treosulfanfludarabine combination was successful in a patient with chronic granulomatous disease and autologous recovery. ${ }^{23}$ Combination with treosulfan in a patient who had rejected the graft but not recovered autologously (UPN 4) resulted in significant mucositis with Achromobacter xylosoxidans sepsis and death, which discourages treosulfan-based conditioning in children with mucositis and aplastic BM.

Another crucial point of the procedure is related to the donor's choice. An analysis shown by Berger et al. identified a superior outcome in a case of using the mother as a donor due to significantly lower relapse incidence. ${ }^{18}$ The explanation of this fact may be sensitization during the pregnancy by the father's haplotype, and in consequence building an antitumor reaction. The expected alloreactivity can be used to improve the donor selection algorithm. In our series, we tested the KIR haplotype and KIR-ligand mismatch, which could have helped in choosing a better donor. Retrospective analysis in 3 out of the 5 leukemic patients showed better KIR haplotype, which may be partially responsible for the lack of acute lymphoblastic leukemia relapses, as was shown in haploSCT with T-cell depletion. ${ }^{24}$ The alloreactivity and anti-leukemic effects after haploSCT with PTCY are exerted through NK-cell activity affected by better KIR haplotype and KIR receptor-ligand mismatch, which should be considered during the donor selection process. ${ }^{25,26}$ The effect of infused NK cells is diminished by the elimination of NK cells with cyclophosphamide infusion. ${ }^{27}$

Another issue observed in our patients was a high incidence of GvHD, although only 1 patient transplanted with PBPC developed cGvHD. Most haploSCTs with PTCY are carried up with BM as a source of stem cells. Transplantation with PBPC and PTCY is reported to show a high incidence of aGvHD and cGvHD (45\% and 53\%, respectively). ${ }^{28}$ This report is particularly worth mentioning due to the fact that all children, even at the age of 1 year, underwent TBI. In the literature, the preference of PBPC over BM as a graft source is associated with an increased risk of aGvHD incidence (stage II-IV: HR-2.1; p < 0.001 and stage III-IV: HR-3.8; $\mathrm{p}<0.001$ ) after haploSCT with PTCY, as shown by Ruggeri et al. ${ }^{29}$ In 1 pediatric series, after PBPC, an excessive $80 \%$ incidence of aGvHD was reported. ${ }^{30}$ Although the $\mathrm{BM}$ is proven to reduce the risk of aGvHD without affecting non-relapse mortality, at the same time the risk of malignancy relapse is increased (HR-1.49; $\mathrm{p}=0.009) .{ }^{31}$ In our series, BM was preferred ( 4 of 5 cases), and in the remaining case, PBPC was selected due to the advanced disease and need for maximal immunotherapeutic effect. Still, the risk of GvHD is not always warranted and both graft rejection and GvHD after haploSCT with PTCY can be reduced by the addition of serotherapy, as reported by Wiebking et al. ${ }^{32}$ The group reported 3 haploSCT in sickle-cell disease, with administration of a treosulfan, fludarabine and thiotepa protocol with pre- and post-transplant cyclophosphamide and low doses of MabCampath, which resulted in full donor engraftment without GvHD incidence. Another strategy has been tried with the addition of ATG, that can decrease the GvHD incidence to less than 20\%. ${ }^{33}$ Thus, serotherapy in haploSCT with PTCY can be recommended in patients with non-malignant disorders, who do not benefit from a T-cell mediated graft-versus-leukemia effect. Reduction of graft rejection risk can be another advantage of serotherapy included in the conditioning backbone.

\section{Conclusions}

Haploidentical stem cell transplantation can be a viable option for patients with advanced malignancies, who relapse after transplantation and are heavily pretreated, but due to limited experience, further trials are required. Alternative, reduced-intensity TBI-free protocols can be used as conditioning in haploSCT with PTCY, especially in pediatric patients.

\section{ORCID iDs}

Elżbieta Wawrzyniak-Dzierżek (D) https://orcid.org/0000-0002-0450-8616 Kornelia Gajek (D) https://orcid.org/0000-0003-0073-7769

Aleksandra Ślęzak (D) https://orcid.org/0000-0001-8780-2062 Blanka Rybka (D) https://orcid.org/0000-0002-4216-0673 Renata Ryczan-Krawczyk (D) https://orcid.org/0000-0002-4936-4951 Ewa Gorczyńska (1) https://orcid.org/0000-0002-5709-6731 Krzysztof Kałwak (D) https://orcid.org/0000-0003-1174-5799 Marek Ussowicz (D) https://orcid.org/0000-0001-5725-4835

\section{References}

1. Reisner $\mathrm{Y}$, Kapoor N, Kirkpatrick D, et al. Transplantation for severe combined immunodeficiency with HLA-A,B,D,DR incompatible parental marrow cells fractionated by soybean agglutinin and sheep red blood cells. Blood. 1983;61(2):341-348. 
2. McNiece I, Briddell R, Stoney G, et al. Large-scale isolation of CD34+ cells using the Amgen cell selection device results in high levels of purity and recovery. J Hematother. 1997;6(1):5-11.

3. Luznik L, Jalla S, Engstrom LW, lannone R, Fuchs EJ. Durable engraftment of major histocompatibility complex-incompatible cells after nonmyeloablative conditioning with fludarabine, low-dose total body irradiation, and posttransplantation cyclophosphamide. Blood. 2001;98(12):3456-3464.

4. Luznik L, O'Donnell PV, Symons HJ, et al. HLA-haploidentical bone marrow transplantation for hematologic malignancies using nonmyeloablative conditioning and high-dose, posttransplantation cyclophosphamide. Biol Blood Marrow Transplant. 2008;14(6):641-650.

5. Bresters D, Lawitschka A, Cugno C, et al. Incidence and severity of crucial late effects after allogeneic HSCT for malignancy under the age of 3 years: TBI is what really matters. Bone Marrow Transplant. 2016; 51(11):1482-1489.

6. Boztug H, Sykora KW, Slatter M, et al. European Society for Blood and Marrow Transplantation analysis of treosulfan conditioning before hematopoietic stem cell transplantation in children and adolescents with hematological malignancies. Pediatr Blood Cancer. 2016;63(1): 139-148.

7. Cooley S, Weisdorf DJ, Guethlein LA, et al. Donor selection for natural killer cell receptor genes leads to superior survival after unrelated transplantation for acute myelogenous leukemia. Blood. 2010;116(14): 2411-2419.

8. Moretta L, Locatelli F, Pende D, Marcenaro E, Mingari MC, Moretta A. Killer Ig-like receptor-mediated control of natural killer cell alloreactivity in haploidentical hematopoietic stem cell transplantation. Blood. 2011;117(3):764-771.

9. Ciurea SO, Zhang MJ, Bacigalupo AA, et al. Haploidentical transplant with posttransplant cyclophosphamide vs matched unrelated donor transplant for acute myeloid leukemia. Blood. 2015;126(8):1033-1040.

10. Gu Z, Wang L, Yuan L, et al. Similar outcomes after haploidentical transplantation with post-transplant cyclophosphamide versus HLAmatched transplantation: A meta-analysis of case-control studies. Oncotarget. 2017;8(38):63574-63586.

11. Pawlowska AB, Cheng JC, Karras NA et al. HLA haploidentical stem cell transplant with pretransplant immunosuppression for patients with sickle cell disease. Biol Blood Marrow Transplant. 2018;24(1):185-189.

12. Llosa NJ, Cooke KR, Chen AR, et al. Reduced-intensity haploidentical bone marrow transplantation with post-transplant cyclophosphamide for solid tumors in pediatric and young adult patients. Biol Blood Marrow Transplant. 2017;23(12):2127-2136.

13. Shima H, Isshiki K, Yamada Y, Yamazaki F, Takahashi T, Shimada H. Successful haploidentical BMT with post-transplant cyclophosphamide for refractory autoimmune pancytopenia after cord blood transplant in pediatric myelodysplastic syndrome. Bone Marrow Transplant. 2017;52(4):653-655.

14. Thakar MS, Bonfim C, Walters MC, et al. Dose-adapted post-transplant cyclophosphamide for HLA-haploidentical transplantation in Fanconi anemia. Bone Marrow Transplant. 2017;52(4):570-573.

15. Bonfim C, Ribeiro L, Nichele S, et al. Haploidentical bone marrow transplantation with post-transplant cyclophosphamide for children and adolescents with Fanconi anemia. Biol Blood Marrow Transplant. 2017;23(2):310-317.

16. Solomon SR, Sizemore CA, Sanacore M, et al. Haploidentical transplantation using $T$ cell replete peripheral blood stem cells and myeloablative conditioning in patients with high-risk hematologic malignancies who lack conventional donors is well tolerated and produces excellent relapse-free survival: Results of a prospective phase II trial. Biol Blood Marrow Transplant. 2012;18(12):1859-1866.

17. Shah NN, Freeman AF, Su H, et al. Haploidentical related donor hematopoietic stem cell transplantation for dedicator-of-cytokinesis 8 deficiency using post-transplantation cyclophosphamide. Biol Blood Marrow Transplant. 2017;23(6):980-990.
18. Berger M, Lanino E, Cesaro S, et al. Feasibility and outcome of haploidentical hematopoietic stem cell transplantation with post-transplant high-dose cyclophosphamide for children and adolescents with hematologic malignancies: An AIEOP-GITMO retrospective multicenter study. Biol Blood Marrow Transplant. 2016;22(5):902-909.

19. Kreetapirom P, Hongeng S, Manuyakorn W, et al. Successful HLA haploidentical HSCT with post-transplant cyclophosphamide in WiskottAldrich syndrome. Bone Marrow Transplant. 2017;52(6):913-914.

20. Ouederni M, Mellouli F, Khaled MB, Kaabi H, Picard C, Bejaoui M. Successful haploidentical stem cell transplantation with post-transplant cyclophosphamide in a severe combined immune deficiency patient: A first report. J Clin Immunol. 2016;36(5):437-440.

21. Bahr TL, Lund T, Sando NM, Orchard PJ, Miller WP. Haploidentical transplantation with post-transplant cyclophosphamide following reduced-intensity conditioning for osteopetrosis: Outcomes in three children. Bone Marrow Transplant. 2016;51(11):1546-1548.

22. Weissert $\mathrm{R}$, Wiendl $\mathrm{H}$, Pfrommer $\mathrm{H}$, et al. Action of treosulfan in myelinoligodendrocyte-glycoprotein-induced experimental autoimmune encephalomyelitis and human lymphocytes. J Neuroimmunol. 2003;144(1-2):28-37.

23. Klaudel-Dreszler MA, Kalwak K, Kurenko-Deptuch M, et al. Treosulfan-based conditioning regimen in a second matched unrelated peripheral blood stem cell transplantation for a pediatric patient with CGD and invasive aspergillosis, who experienced initial graft failure after RIC. Int J Hematol. 2009;90(5):571-575.

24. Oevermann L, Michaelis SU, Mezger M, et al. KIR B haplotype donors confer a reduced risk for relapse after haploidentical transplantation in children with ALL. Blood. 2014;124(17):2744-2747.

25. Wanquet A, Bramanti S, Harbi S, et al. Killer cell immunoglobulin-like receptor-ligand mismatch in donor versus recipient direction provides better graft-versus-tumor effect in patients with hematologic malignancies undergoing allogeneic T cell-replete haploidentical transplantation followed by post-transplant cyclophosphamide. Biol Blood Marrow Transplant. 2018;24(3):549-554.

26. Solomon SR, Aubrey MT, Zhang X, et al. Selecting the best donor for haploidentical transplant: Impact of HLA, killer cell immunoglobulin-like receptor genotyping, and other clinical variables. Biol Blood Marrow Transplant. 2018;24(4):789-798.

27. Russo A, Oliveira G, Berglund S, et al. NK cell recovery after haploidentical HSCT with posttransplant cyclophosphamide: Dynamics and clinical implications. Blood. 2018;131(2):247-262.

28. Dufort G, Castillo L, Pisano S, et al. Haploidentical hematopoietic stem cell transplantation in children with high-risk hematologic malignancies: Outcomes with two different strategies for GvHD prevention. Ex vivo T-cell depletion and post-transplant cyclophosphamide: 10 years of experience at a single center. Bone Marrow Transplant. 2016;51(10):1354-1360.

29. Ruggeri A, Labopin M, Bacigalupo A, et al. Bone marrow versus mobilized peripheral blood stem cells in haploidentical transplants using posttransplantation cyclophosphamide. Cancer. 2018;124(7):1428-1437.

30. Jaiswal SR, Chakrabarti A, Chatterjee S, Ray K, Chakrabarti S. Haploidentical transplantation in children with unmanipulated peripheral blood stem cell graft: The need to look beyond post-transplantation cyclophosphamide in younger children. Pediatr Transplant. 2016;20(5):675-682.

31. Bashey A, Zhang MJ, McCurdy SR, et al. Mobilized peripheral blood stem cells versus unstimulated bone marrow as a graft source for T-cell-replete haploidentical donor transplantation using post-transplant cyclophosphamide. J Clin Oncol. 2017;35(26):3002-3009.

32. Wiebking V, Hütker S, Schmid I, Immler S, Feuchtinger T, Albert MH. Reduced toxicity, myeloablative HLA-haploidentical hematopoietic stem cell transplantation with post-transplantation cyclophosphamide for sickle cell disease. Ann Hematol. 2017;96(8):1373-1377.

33. Anurathapan U, Hongeng S, Pakakasama S, et al. Hematopoietic stem cell transplantation for homozygous $\beta$-thalassemia and $\beta$-thalassemia/ hemoglobin E patients from haploidentical donors. Bone Marrow Transplant. 2016;51(6):813-818. 